\title{
Depo Yeri Seçimi için Aralık Tip-2 Bulanık ÇKKV Tabanlı Hibrit Bir Yaklaşım
}

\author{
Ahmet ÇALIK ${ }^{1}$
}

$\ddot{\mathrm{O} z}$

Doğru yerden doğru yere mümkün olan en iyi kalitede ürün teslim etmeyi amaçlayan çoğu şirket için, doğru depo yeri seçimi stratejik başarı için çok önemlidir. Şirketlerin doğru konum kararını vermesi küresel iş ortamında her geçen gün belirsiz hale geldiğinden, yeni bir depo yeri hakkında sağlam ve geleceğe dönük bir karar vermek büyük önem taşımaktadır. $\mathrm{Bu}$ nedenle, doğru depo yeri seçiminin belirlenmesi, başarılı bir tedarik zinciri sisteminin geliştirilmesindeki temel problemlerden biri olmuştur. Bu çalışmada, uygun depo yerini seçmek için aralık tip-2 bulanık kümeleriyle genişletilen çok kriterli karar verme (ÇKKV) yönteminin sunulması amaçlanmaktadır. Önerilen yaklaşım, karar vermede uzmanların yargılarında ve ifadelerinde yer alan belirsizliğinin üstesinden gelmek için aralık tip-2 bulanık ortam altında AHP ve TOPSIS yöntemlerini içermektedir. Bulanık AHP, depo seçiminde uzmanlarca belirlenen kriterlerin ağırlıklarını belirlemek için kullanılmış; ardından aralık tip-2 yamuksal bulanık sayılar ile alternatif depoların sıralamasını elde etmek için TOPSIS yöntemi kullanılmıştır. Önerilen metodolojinin uygulamasını göstermek için, Türkiye'de yeni bir depo açmak isteyen firma için gerçek verileri kullanarak bir çalısma yürütülmüştür.

Anabtar Kelimeler: Aralık Tip-2 Bulanık AHP, Aralık Tip-2 Bulanık TOPSIS, Depo Yeri Seçimi.

\section{A Hybrid Approach based on Interval Type-2 Fuzzy MCDM for Warehouse Site Selection}

\section{Abstract}

For most companies that aim at delivering the best possible quality product from the right place to the right place, choosing the right warehouse location is very important for operational success. It is of great importance to make a right and future-oriented decision about a new warehouse location, as companies' decision to make the right position is becoming more and more ambiguous in the global business environment. Therefore, choosing the right warehouse location is one of the main problems in the development of a successful supply chain system. In this study, it is aimed to present the multi-criteria decision making (MCDM) method, which is expanded by the interval type-2 fuzzy sets to select the appropriate warehouse location. The proposed approach includes the AHP and TOPSIS methods under the interval type-2 fuzzy environment to overcome the uncertainty in the judgment and statements of the experts in decision-making. Fuzzy AHP is used to determine the weight of criteria determined by experts in the selection of warehouses; then the TOPSIS method is used to obtain the ranking of alternative depots with spacing type-2 trapezoidal fuzzy numbers. To show the proposed application of the methodology, a study is carried out using real data for companies wishing to open a new store in Turkey.

Key Words: Interval Type-2 Fuzzy AHP, Interval Type-2 Fuzzy TOPSIS, Warehouse Site Selection

Atıf İçin / Please Cite As:

Çalık, A. (2020). Depo yeri seçimi için aralık Tip-2 bulanık ÇKKV tabanlı hibrit bir yaklaşım. Manas Sosyal Arastirmalar Dergisi, 9(1), 101-114.

Geliş Tarihi / Received Date: 10.01.2019

Kabul Tarihi / Accepted Date: 18.06.2019

\footnotetext{
${ }^{1}$ Dr. Öğr. Üyesi - KTO Karatay Üniversitesi İktisadi ve İdari Bilimler Fakültesi, ahmetcalik51@gmail.com ORCID: 0000-0002-6796-0052
} 


\section{Giriş}

Lojistik ve tedarik zinciri yönetimi günümüzün küresel pazarında temel rolü oynamaktadır. Küresel rekabet ve ekonomik değişimler şirketlerin hayatta kalması için zorluk oluşturmaktadır. Bu tehditler şirketlerin bağımsız olarak ayakta kalamayacaklarını fark etmelerine yol açmış ve tedarik zinciri yönetimi olarak çeşitli aktörler ile yakın koordinasyon içinde çalışmak zorunda bırakmıştır. Tedarik zincirinde ağlar arasında çeşitli dügüumler ve bunlar arasında ürünlerin taşınması yer alır. Düğümler tedarikçiler, şirketler, depolar, dağıtım merkezleri ve müşterilerden oluşmaktadır (Dey vd., 2016). Etkin bir dağıtım ağ1 oluşturabilmenin en önemli aşaması ise depo yerlerinin seçimidir.

Dağıım depolarının optimum konumu, lojistik sistemlerin optimizasyonunun önemli bir parçasıdır. Bir depo, ürünlerin korunması ve depolanması için ticari bir binadır. Depolar üreticiler, ithalatçılar, ihracatçılar, perakendeciler, nakliye şirketleri vb. tarafindan kullanılmaktadır. Frazelle (2015) depoların modern tedarik zincirlerinin önemli bir unsuru olduğuna ve günümüzde işletmelerin başarısında veya başarısızlı̆ında hayati bir rol oynadığına dikkat çekmiştir. Günümüz dünyasında, bir depo yeri seçimi, lojistik sistemlerin optimizasyonunda en önemli ve stratejik kararlardan biri haline gelmiştir.

Bir deponun yeri genellikle tedarik zinciri optimizasyonunda en önemli ve stratejik kararlardan birisidir. Bu noktada lojistik yöneticilerinin en önemli karar alma süreçlerinden biri depo yerinin seçimi kararıdır (Chen, 2001). Uzun vadeli bir karardır ve pek çok nicel ve nitel kriterden etkilenir. Bununla birlikte, bazı kriterler o kadar önemlidir ki, kararlarda baskın olarak ön plana çıkmaktadırlar.

Depo yeri problemi, politik çevre, pazarlara yakınlık ve müşteriler, tedarikçi ağları, genişleme potansiyeli, ulaşım sistemlerinin kullanılabilirliği, hizmet kalitesi, yaşam kalitesi, kültür sorunları gibi çelişen kriterler içeren tipik bir ÇKKV problemidir. Karar vermenin karmaşık sürecinde, çeşitli belirsizlik unsurlarının yaygın olduğu açıktır. Karar alıcıların değerlendirmeleri öznel ve dilsel yargılar ile ifade edildiğinden, kesin sayısal değerler doğru sonuç vermeyecektir. Bu nedenle, çalışmada ÇKKV yöntemleri bulanık küme teorisi ile birleştirilmiştir (Baykasoğlu ve Gölcük, 2017). Bununla birlikte, tip-2 bulanık kümeler daha fazla belirsizlikle başa çıkabildikleri ve daha güvenilir sonuçlar üretebildikleri için (Çelik vd. 2013) karar vericilerin kesin olmayan bilgilerinin modellenmesi için sıklıkla kullanılmaktadır.

Depo yeri seçiminin tedarik zinciri yönetiminde önemli bir problem olması nedeniyle, birçok uygulayıcı ve araştırmacı son yıllarda bu konuya büyük önem vermiştir. Aktepe ve Ersöz (2014), depo yeri seçimine kriterlerin ağırlıklandırılmasında AHP yöntemi ve alternatiflerin sıralanmasında VIKOR ve MOORA yöntemlerini kullanarak bir döküm fabrikası için depo yeri seçimini araştırmışlardır. Ashrafzadeh vd. (2012) İran'da büyük bir şirketin depo yeri seçim problemini bulanık TOPSIS yöntemi ile birlikte ele almışlardır. Büyüközkan ve Uztürk (2017) yeşil depo seçimi için 2-tuple dilsel modeli, QFD ve TOPSIS yöntemine dayalı entegre bir grup karar verme tekniğini önermişlerdir. Chai vd. (2013) aralık değerli sezgisel bulanık ortam altında en karlı depo seçimi için yeni bir kural tabanlı karar modeli önermişlerdir. Chen (2001) alternatiflerin değerlendirmeleri ve her bir kriterin ağırlı̆̆ı üçgensel bulanık sayılarla ifade edilebilen dilsel değişkenler tarafindan açıklanan bir model önererek dağıtım merkezi konum seçimi problemini çözmüştür. Asır ve Erol (2016) AHP, basit ağırlıklı toplama, COPRAS ve MOORA yöntemlerini en uygun depo yerinin belirlenmesi için kullanmışlardır. Demirel, ve diğ, (2010) depo yeri seçiminde kriterler birbirleri arasındaki etkileşimleri içerdiğinde, Choquet integralinin çözüm için mükemmel bir araç sunduğunu göstermişlerdir. Dey, ve diğ., (2013) karar vericilere yardımcı olmada kriter ağırlıkları ve depo yerlerinin değerlendirmeleri için bulanık küme teorisine dayalı seçim metodolojisini geliştirmişlerdir. Dey vd. (2016) bulanık ortam altında TOPSIS, basit ağırlıklı toplama ve MOORA yöntemlerini depo yeri seçimi için kullanmışlardır. Karmaker ve Saha, (2015) mevcut beş konumu karşılaştırarak en iyi depo konumunu değerlendirmek için bulanık AHP, TOPSIS ve bulanık TOPSIS yöntemlerini kullanarak karşılaştırma yapmışlardır. Huang vd. (2015) toplam gelen ve giden nakliye masraflarını ve toplam depo inşaat maliyetlerini en aza indirgemeye içeren bir model ile depolar için yer seçimi modelini sunmuşlardır. Jha vd. (2018) Hint kimyasal endüstrileri için sürdürülebilir depo seçiminde 14 başarı faktörlerini tanımlayarak ve yorumlayıcı yapısal modelleme ile kriterler arasındaki ilişkiyi araştırmışlardır. Kabak ve Keskin (2018) AHP yöntemi ile dokuz kriterin ağırlığını belirlemişler, daha sonra bulunan ağırlıkları coğrafi bilgi sisteminde kullanarak Marmara Bölgesi'nde kurulacak bir patlayıcı ve mühimmat deposu için en uygun yeri belirlemişlerdir. Özcan vd. (2011) yaygın olarak kullanılan üç temel metodolojinin, AHP, TOPSIS ve ELECTRE, karşılaştırmalı analizi depo yeri seçimi için yapılmıştır. Vlachopoulou vd. (2001) depo yeri seçim süreci için coğrafi bir karar destek sistemi geliştirmişlerdir. 
Bu çalışmada, aralık tip-2 bulanık kümelere dayalı bir ÇKKV metodolojisi kullanarak Türkiye'de alüminyum sektöründe faaliyet gösteren bir şirket için alternatif dört depoyu karşılaştırarak en iyi depo yerinin belirlenmesi amaçlanmaktadır. Bu amaçla, en iyi alternatif yeri bulmak için aralık tip-2 bulanık ortam altında AHP ve TOPSIS karar verme yöntemleri kullanılmıştır. Değerlendirme sürecinde kriter ağılıkları aralık tip-2 bulanık AHP yöntemi kullanılarak hesaplanmış ve alternatiflerin sıralaması aralık tip-2 bulanık TOPSIS yöntemi kullanılarak elde edilmiştir.

Bu çalışmanın geri kalanı şu şekilde düzenlenmiştir. İkinci bölüm, önerilen metodolojini detaylarını ve teorik altyapısını açıklamaya ayrılmıştı. Geliştirilen metodolojinin çerçevesi ve kullanılan bulanık karar verme yaklaşımlarının adım adım bir tasviri sağlanmıştır. Üçüncü bölümde, çalışmanın uygulaması gösterilerek sonuçlar tartışılmıştır. Son olarak, dördüncü bölüm çalışmayı sonuçlandırmakta ve bulguları özetlemektedir.

\section{Önerilen Metodoloji}

Bu bölümde önerilen metodoloji tanıtılmış ve işlem adımları verilmiştir. Önerilen metodoloji üç temel adımdan oluşmaktadır: (1) Modelde kullanılacak kriterler, alternatifler ve dilsel değişkenlerin tanımlanması (2) Kriter ağırlıklarının belirlenmesi için aralık tip-2 AHP yönteminin kullanılması (3) Alternatifleri sıralamak için aralık tip-2 bulanık TOPSIS yönteminin uygulanması. Yeni depo yerinin seçimi için önerilen metodolojinin şematik diyagramı Şekil 1'de gösterilmiştir. Aşamalar aşağıdaki gibidir:

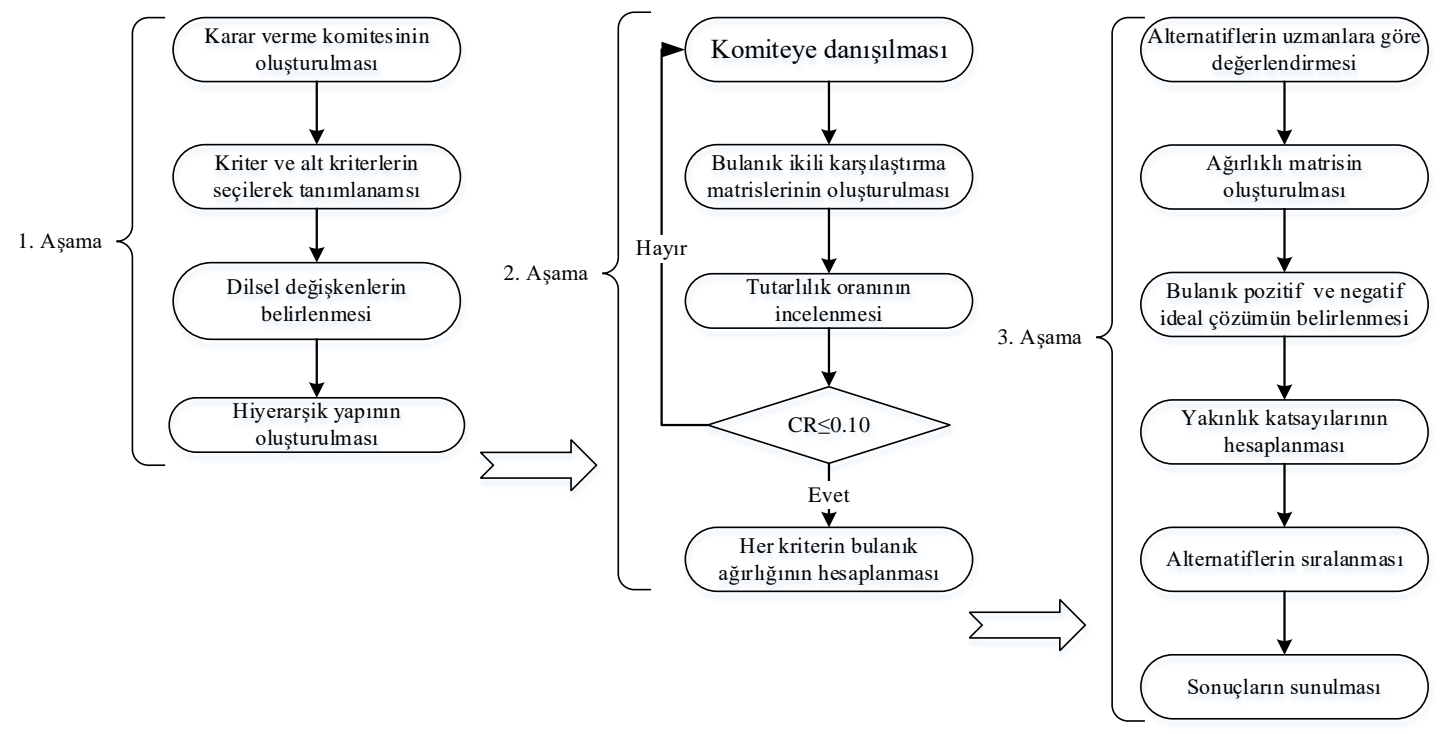

Şekil 1.Önerilen Metodolojinin Adimlar

\section{Aralık Tip-2 Bulanık Kümeler}

$\mathrm{Bu}$ bölümde tip-2 bulanık kümeler ve aralık tip-2 bulanık kümelere ilişkin temel kavramlar ve tanımlamalar (Çelik vd., 2013; Kahraman vd., 2014) kaynaklarından yararlanılarak açıklanımıştır.

Tanım 1:X evrensel kümesine ait bir $\tilde{\tilde{A}}$ tip-2 bulanık küme, $\mu_{\tilde{A}}(x)$ tip-2 bulanık üyelik fonksiyonu ile aşağıdaki gibi ifade edilir.

$\tilde{\tilde{A}}=\left\{\left((x, u), \mu_{\tilde{A}}(x, u)\right) \mid \forall x \in X, \forall u \in J_{x} \subseteq[0,1], 0 \leq \mu_{\tilde{\tilde{A}}}(x, u) \leq 1\right\}$

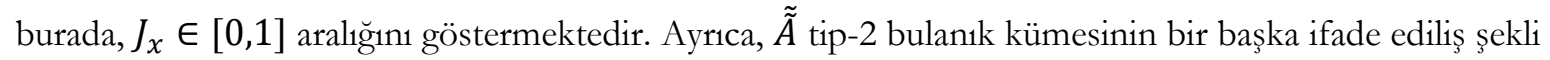
aşağıdaki gibidir:

$\tilde{\tilde{A}}=\int_{x \in X} \int_{u \in J_{x}} \mu_{\tilde{A}}(x, u) /(x, u)$

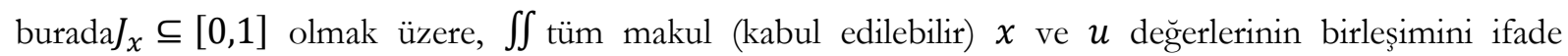
etmektedir. 
Tanım 2:X evrensel kümesine ait $\tilde{\tilde{A}}$ tip-2 bulanık kümesini tanımlayan tip-2 üyelik fonksiyonunu $\mu_{\tilde{\tilde{A}}}$ olarak gösterilsin. Eğer bütün $\mu_{\tilde{A}}(x, u)=1$ ise, $\tilde{\tilde{A}}$ kümesine aralık tip-2 bulanık küme adı verilir. Bir aralık tip-2 bulanık küme, $\tilde{\tilde{A}}$ tip-2 bulanık kümenin özel bir durumu olarak kabuk edilir ve aşağıdaki şekilde gösterilebilir:

$\tilde{\tilde{A}}=\int_{x \in X} \int_{u \in J_{x}} 1 /(x, u)$

$\operatorname{burada}_{x} \subseteq[0,1]$ dir.

Tanım 3: Aralık tip-2 bulanık kümesinin alt ve üst üyelik fonksiyonları sırasıyla tip-1 üyelik fonksiyonudur. Chen ve Lee (2010a) çalışmalarında bulanık çok kriterli grup karar verme problemlerinin çözümünde aralık tip-2 bulanık kümeleri kullanmak için yeni bir yöntem önermişlerdir. Bu yönteme göre, aralık tip-2 bulanık kümelerin referans noktaları ve üst ve alt üyelik fonksiyonlarının yükseklikleri, tip-2 bulanık kümelerini karakterize etmek için kullanılmıstır. Şekil 2'de yamuksal bir aralık tip-2 bulanık küme gösterilmektedir Yamuksal bir aralı tip-2 bulanı kümeler $\tilde{\tilde{A}}_{i}=\left(\tilde{A}_{i}^{U} ; \tilde{A}_{i}^{L}\right)=$ $\left(\left(a_{i 1}^{U}, a_{i 2}^{U}, a_{i 3}^{U}, a_{i 4}^{U} ; H_{1}\left(\tilde{A}_{i}^{U}\right), H_{2}\left(\tilde{A}_{i}^{U}\right)\right),\left(a_{i 1}^{L}, a_{i 2}^{L}, a_{i 3}^{L}, a_{i 4}^{L} ; H_{1}\left(\tilde{A}_{i}^{L}\right), H_{2}\left(\tilde{A}_{i}^{L}\right)\right)\right)$ burada $\tilde{A}_{i}^{U}$ ve $\tilde{A}_{i}^{L}$ tip-1 bulanık kümeleri, $a_{i 1}^{U}, a_{i 2}^{U}, a_{i 3}^{U}, a_{i 4}^{U}, a_{i 1}^{L}, a_{i 2}^{L}, a_{i 3}^{L}$ ve $a_{i 4}^{L}$ yamuksal aralık tip-2 bulanık kümesi $\tilde{\tilde{A}}_{i}$ kümesinin referans noktalarını, $\quad H_{j}\left(\tilde{A}_{i}^{U}\right) ; 1 \leq j \leq 2$ olmak üzere $a_{i(j+1)}^{U}$ elemanının $\tilde{A}_{i}^{U}$ üst yamuksal üyelik fonksiyonundaki üyelik değerini, $H_{j}\left(\tilde{A}_{i}^{L}\right) ; 1 \leq j \leq 2$ olmak üzere $a_{i(j+1)}^{L}$ elemanının $\tilde{A}_{i}^{L}$ alt yamuksal üyelik fonksiyonundaki üyelik değerini ifade ettiğinde ve $H_{1}\left(\tilde{A}_{i}^{U}\right) \in[0,1], H_{2}\left(\tilde{A}_{i}^{U}\right) \in[0,1], H_{1}\left(\tilde{A}_{i}^{L}\right) \in$ $[0,1], H_{2}\left(\tilde{A}_{i}^{L}\right) \in[0,1]$ ve $1 \leq i \leq n$ koşullarını sağladığında Eşitlik (1) ile gösterilir.

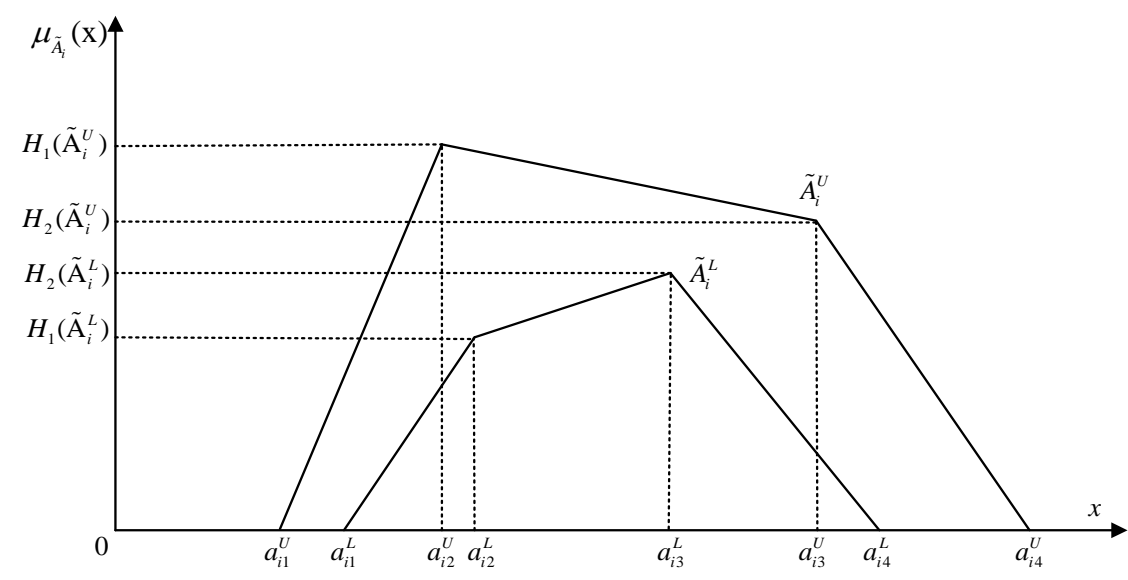

Şekil 2. Yamuksal aralık tip-2 bulanı saymm üyelik fonksiyonu

Tanım 4:Yamuksal aralık tip-2 bulanık kümeleri arasındaki toplama işlemi aşağıdaki şekilde gösterilir.

$$
\begin{gathered}
\tilde{A}_{1}=\left(\tilde{A}_{1}^{U}, \tilde{A}_{1}^{L}\right)=\left(\left(a_{11}^{U}, a_{12}^{U}, a_{13}^{U}, a_{14}^{U} ; H_{1}\left(\tilde{A}_{1}^{U}\right), H_{2}\left(\tilde{A}_{1}^{U}\right)\right),\left(a_{11}^{L}, a_{12}^{L}, a_{13}^{L}, a_{14}^{L} ; H_{1}\left(\tilde{A}_{1}^{L}\right), H_{2}\left(\tilde{A}_{1}^{L}\right)\right)\right) \\
\tilde{\tilde{A}}_{2}=\left(\tilde{A}_{2}^{U}, \tilde{A}_{2}^{L}\right)=\left(\left(a_{21}^{U}, a_{22}^{U}, a_{23}^{U}, a_{24}^{U} ; H_{1}\left(\tilde{A}_{2}^{U}\right), H_{2}\left(\tilde{A}_{2}^{U}\right)\right),\left(a_{21}^{L}, a_{22}^{L}, a_{23}^{L}, a_{24}^{L} ; H_{1}\left(\tilde{A}_{2}^{L}\right), H_{2}\left(\tilde{A}_{2}^{L}\right)\right)\right) \\
\tilde{A}_{1} \oplus \tilde{A}_{2}=\left(\tilde{A}_{1}^{U}, \tilde{A}_{1}^{L}\right) \oplus\left(\tilde{A}_{2}^{U}, \tilde{A}_{2}^{L}\right) \\
\left(\left(a_{11}^{U}+a_{21}^{U}, a_{12}^{U}+a_{22}^{U}, a_{13}^{U}+a_{23}^{U}, a_{14}^{U}+a_{24}^{U} ; \min \left(H_{1}\left(\tilde{A}_{1}^{U}\right) ; H_{1}\left(\tilde{A}_{2}^{U}\right)\right)\right), \min \left(H_{2}\left(\tilde{A}_{1}^{U}\right) ; H_{2}\left(\tilde{A}_{2}^{U}\right)\right)\right), \\
\left(\left(a_{11}^{L}+a_{21}^{L}, a_{12}^{L}+a_{22}^{L}, a_{13}^{L}+a_{23}^{L}, a_{14}^{L}+a_{24}^{L} ; \min \left(H_{1}\left(\tilde{A}_{1}^{L}\right) ; H_{1}\left(\tilde{A}_{2}^{L}\right)\right)\right), \min \left(H_{2}\left(\tilde{A}_{1}^{L}\right) ; H_{2}\left(\tilde{A}_{2}^{L}\right)\right)\right)
\end{gathered}
$$

Tanım 5:Yamuksal aralık tip-2 bulanık kümeleri arasındaki çıkarma işlemi aşağıdaki şekilde gösterilir.

$$
\tilde{A}_{1}=\left(\tilde{A}_{1}^{U}, \tilde{A}_{1}^{L}\right)=\left(\left(a_{11}^{U}, a_{12}^{U}, a_{13}^{U}, a_{14}^{U} ; H_{1}\left(\tilde{A}_{1}^{U}\right), H_{2}\left(\tilde{A}_{1}^{U}\right)\right),\left(a_{11}^{L}, a_{12}^{L}, a_{13}^{L}, a_{14}^{L} ; H_{1}\left(\tilde{A}_{1}^{L}\right), H_{2}\left(\tilde{A}_{1}^{L}\right)\right)\right)
$$




$$
\begin{gathered}
\tilde{A}_{2}=\left(\tilde{A}_{2}^{U}, \tilde{A}_{2}^{L}\right)=\left(\left(a_{21}^{U}, a_{22}^{U}, a_{23}^{U}, a_{24}^{U} ; H_{1}\left(\tilde{A}_{2}^{U}\right), H_{2}\left(\tilde{A}_{2}^{U}\right)\right),\left(a_{21}^{L}, a_{22}^{L}, a_{23}^{L}, a_{24}^{L} ; H_{1}\left(\tilde{A}_{2}^{L}\right), H_{2}\left(\tilde{A}_{2}^{L}\right)\right)\right) \\
\tilde{A}_{1} \ominus \tilde{A}_{2}=\left(\tilde{A}_{1}^{U}, \tilde{A}_{1}^{L}\right) \ominus\left(\tilde{A}_{2}^{U}, \tilde{A}_{2}^{L}\right) \\
\left(\left(a_{11}^{U}-a_{21}^{U}, a_{12}^{U}-a_{22}^{U}, a_{13}^{U}-a_{23}^{U}, a_{14}^{U}-a_{24}^{U} ; \min \left(H_{1}\left(\tilde{A}_{1}^{U}\right) ; H_{1}\left(\tilde{A}_{2}^{U}\right)\right)\right), \min \left(H_{2}\left(\tilde{A}_{1}^{U}\right) ; H_{2}\left(\tilde{A}_{2}^{U}\right)\right)\right), \\
\left(\left(a_{11}^{L}-a_{21}^{L}, a_{12}^{L}-a_{22}^{L}, a_{13}^{L}-a_{23}^{L}, a_{14}^{L}-a_{24}^{L} ; \min \left(H_{1}\left(\tilde{A}_{1}^{L}\right) ; H_{1}\left(\tilde{A}_{2}^{L}\right)\right)\right), \min \left(H_{2}\left(\tilde{A}_{1}^{L}\right) ; H_{2}\left(\tilde{A}_{2}^{L}\right)\right)\right)
\end{gathered}
$$

Tanım 6:Yamuksal aralık tip-2 bulanık kümeleri arasındaki çarpma işlemi aşağıdaki şekilde gösterilir.

$$
\begin{gathered}
\tilde{A}_{1}=\left(\tilde{A}_{1}^{U}, \tilde{A}_{1}^{L}\right)=\left(\left(a_{11}^{U}, a_{12}^{U}, a_{13}^{U}, a_{14}^{U} ; H_{1}\left(\tilde{A}_{1}^{U}\right), H_{2}\left(\tilde{A}_{1}^{U}\right)\right),\left(a_{11}^{L}, a_{12}^{L}, a_{13}^{L}, a_{14}^{L} ; H_{1}\left(\tilde{A}_{1}^{L}\right), H_{2}\left(\tilde{A}_{1}^{L}\right)\right)\right) \\
\tilde{A}_{2}=\left(\tilde{A}_{2}^{U}, \tilde{A}_{2}^{L}\right)=\left(\left(a_{21}^{U}, a_{22}^{U}, a_{23}^{U}, a_{24}^{U} ; H_{1}\left(\tilde{A}_{2}^{U}\right), H_{2}\left(\tilde{A}_{2}^{U}\right)\right),\left(a_{21}^{L}, a_{22}^{L}, a_{23}^{L}, a_{24}^{L} ; H_{1}\left(\tilde{A}_{2}^{L}\right), H_{2}\left(\tilde{A}_{2}^{L}\right)\right)\right) \\
\tilde{A}_{1} \otimes \tilde{A}_{2}=\left(\tilde{A}_{1}^{U}, \tilde{A}_{1}^{L}\right) \otimes\left(\tilde{A}_{2}^{U}, \tilde{A}_{2}^{L}\right) \\
\left(\left(a_{11}^{U} \times a_{21}^{U}, a_{12}^{U} \times a_{22}^{U}, a_{13}^{U} \times a_{23}^{U}, a_{14}^{U} \times a_{24}^{U} ; \min \left(H_{1}\left(\tilde{A}_{1}^{U}\right) ; H_{1}\left(\tilde{A}_{2}^{U}\right)\right)\right), \min \left(H_{2}\left(\tilde{A}_{1}^{U}\right) ; H_{2}\left(\tilde{A}_{2}^{U}\right)\right)\right), \\
\left(\left(a_{11}^{L} \times a_{21}^{L}, a_{12}^{L} \times a_{22}^{L}, a_{13}^{L} \times a_{23}^{L}, a_{14}^{L} \times a_{24}^{L} ; \min \left(H_{1}\left(\tilde{A}_{1}^{L}\right) ; H_{1}\left(\tilde{A}_{2}^{L}\right)\right)\right), \min \left(H_{2}\left(\tilde{A}_{1}^{L}\right) ; H_{2}\left(\tilde{A}_{2}^{L}\right)\right)\right)
\end{gathered}
$$

Tanım 7:Yamuksal aralık tip-2 bulanık kümeler ve skalerk arasındaki aritmetik işlemler aşağıdaki şekilde gösterilir.

$$
\begin{aligned}
& \quad \tilde{\tilde{A}}_{1}=\left(\tilde{A}_{1}^{U}, \tilde{A}_{1}^{L}\right)=\left(\left(a_{11}^{U}, a_{12}^{U}, a_{13}^{U}, a_{14}^{U} ; H_{1}\left(\tilde{A}_{1}^{U}\right), H_{2}\left(\tilde{A}_{1}^{U}\right)\right),\left(a_{11}^{L}, a_{12}^{L}, a_{13}^{L}, a_{14}^{L} ; H_{1}\left(\tilde{A}_{1}^{L}\right), H_{2}\left(\tilde{A}_{1}^{L}\right)\right)\right) \\
& k \tilde{\tilde{A}}_{1}=\left(\left(k \times a_{11}^{U}, k \times a_{12}^{U}, k \times a_{13}^{U}, k \times a_{14}^{U} ; H_{1}\left(\tilde{A}_{1}^{U}\right), H_{2}\left(\tilde{A}_{1}^{U}\right)\right),\left(k \times a_{11}^{L}, k \times a_{12}^{L}, k \times a_{13}^{L}, k \times\right.\right. \\
& \left.\left.a_{14}^{L} ; H_{1}\left(\tilde{A}_{1}^{L}\right), H_{2}\left(\tilde{A}_{1}^{L}\right)\right)\right) \\
& \frac{\tilde{A}_{1}}{k}=\left(\left(\frac{1}{k} \times a_{11}^{U}, \frac{1}{k} \times a_{12}^{U}, \frac{1}{k} \times a_{13}^{U}, \frac{1}{k} \times a_{14}^{U} ; H_{1}\left(\tilde{A}_{1}^{U}\right), H_{2}\left(\tilde{A}_{1}^{U}\right)\right),\left(\frac{1}{k} \times a_{11}^{L}, \frac{1}{k} \times a_{12}^{L}, \frac{1}{k} \times a_{13}^{L}, \frac{1}{k} \times\right.\right. \\
& \left.\left.a_{14}^{L} ; H_{1}\left(\tilde{A}_{1}^{L}\right), H_{2}\left(\tilde{A}_{1}^{L}\right)\right)\right)
\end{aligned}
$$

buradak $>0$ olmalidir.

\section{Aralık Tip-2 Bulanık AHP Yöntemi}

Kahraman vd. (2014) çalışmalarında, Buckley'in (1985) tip-1 bulanık kümelere dayalı bulanık AHP yöntemini aralık tip-2 bulanık kümelere göre düzenlemişlerdir. Aşağıda bu yöntemin adımları açıklanmıştır:

Adım 1: Problemin tanımı ve probleme uygun olarak amacı belirlenir.

Adım 2: Problemin kriterler, alt kriterler ve alternatiflerde dâhil olmak üzere hiyerarşik yapısı belirlenir.

Adım 3: Bütün kriterler arasındaki bulanık ikili karşılaştırma matrisi oluşturulur. İkili karşılaştırma matrisini oluşturmak için uzmanlar dilsel değişkenleri kullanırlar. Dilsel değişkenler ve bunların aralık tip-2 bulanık ölçekleri Tablo 1'de verilmiştir. Dilsel değişkenlerin kullanılması ile Eşitlik (9)'daki gibi bulanık ikili karşılaştırma matrisleri oluşturulur. 
Tablo 1. Dilsel Terimler ve Karşılık Gelen Aralık Tip-2 Bulanı Saylar

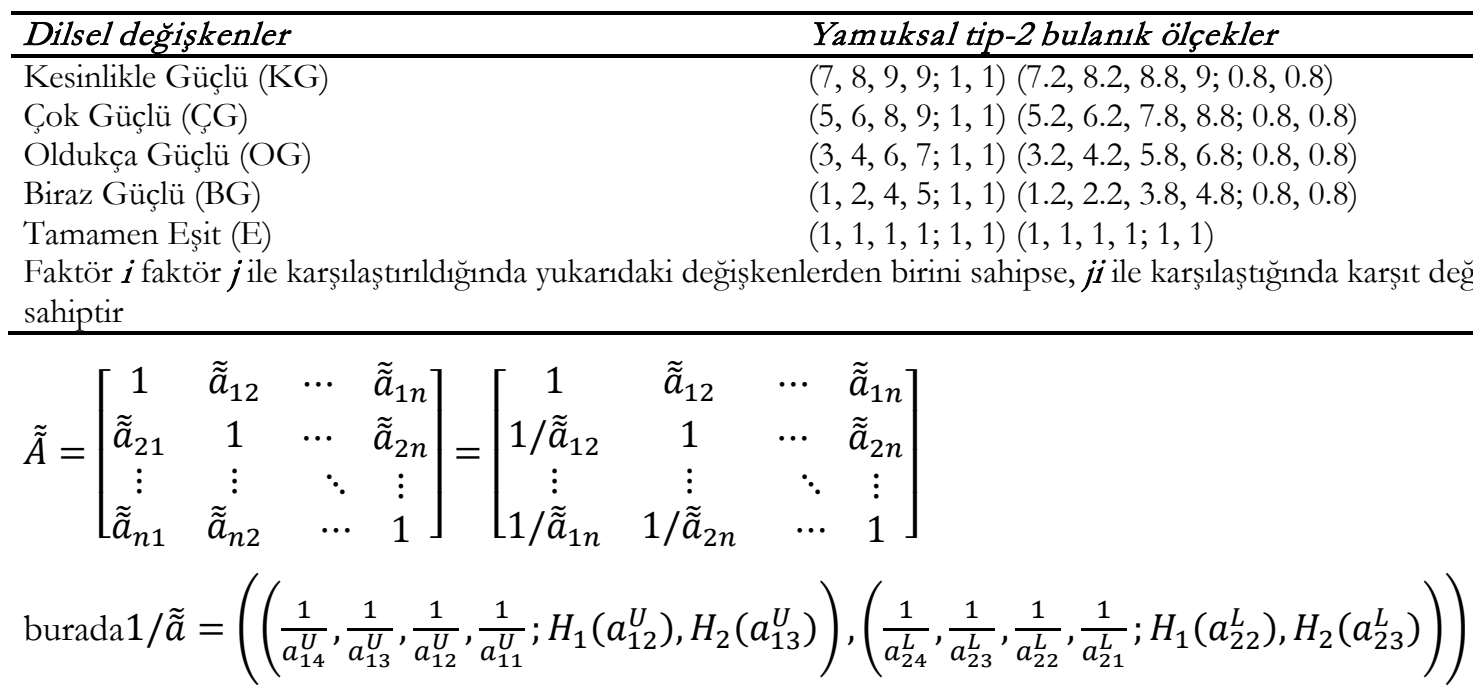

Adım 4: Bulanık ikili karşılaştırma matrislerinin tutarlılıkları incelenir. Bu amaçla bulanık ikili karşılaştırma matrisleri durulaştırılır ve tutarlılıkları incelenir. Ĕger tutarsızlık tespit edilirse uzmanlardan yeniden değerlendirme yapması istenir.

Adım 5: Uzmanların görüşleri geometrik ortalama kullanılarak toplanılır. Her bir satırın geometrik ortalaması $\tilde{\tilde{r}}_{i}$ aşağıdaki gibi hesap edilir:

$\tilde{\tilde{r}}_{i}=\left[\tilde{\tilde{a}}_{i 1} \otimes \ldots \otimes \tilde{\tilde{a}}_{i \mathrm{n}}\right]^{1 / n}$

burada

$$
\sqrt[n]{\tilde{\tilde{a}}_{i j}}=\left(\left(\sqrt[n]{\tilde{\tilde{a}}_{i j 1}^{U},} \sqrt[n]{\tilde{\tilde{a}}_{i j 2}^{U}}, \sqrt[n]{\tilde{\tilde{a}}_{i j 3}^{U},} \sqrt[n]{\tilde{\tilde{a}}_{i j 4}^{U}} ; H_{1}^{U}\left(a_{i j}\right), H_{2}^{U}\left(a_{i j}\right)\right),\left(\sqrt[n]{\tilde{\tilde{a}}_{i j 1}^{L}}, \sqrt[n]{\tilde{\tilde{a}}_{i j 2}^{L},} \sqrt[n]{\tilde{\tilde{a}}_{i j 3}^{L},} \sqrt[n]{\tilde{\tilde{a}}_{i j 4}^{L}} ; H_{1}^{L}\left(a_{i j}\right), H_{2}^{L}\left(a_{i j}\right)\right)\right)
$$

Adım 6: Her bir kriterin bulanık ağırlıkları hesap edilir. Bu amaçla ilk önce her bir satırın geometrik ortalaması olan $\tilde{\tilde{r}}_{i}$ hesaplanır. $i$.kriterin bulanık ağırlı̆̆1 $\widetilde{\widetilde{W}}_{i}$ aşağıdaki şekilde hesaplanır:

$\widetilde{\widetilde{w}}_{i}=\tilde{r}_{i} \otimes\left[\tilde{r}_{1} \oplus \ldots \oplus \tilde{r}_{i} \oplus \ldots \oplus \tilde{\tilde{r}}_{n}\right]^{-1}$

burada,

$$
\begin{aligned}
& \frac{\tilde{\tilde{a}}_{i j}}{\tilde{\tilde{b}}_{i j}}=\left(\frac{a_{1}^{U}}{b_{4}^{U}}, \frac{a_{2}^{U}}{b_{3}^{U}}, \frac{a_{3}^{U}}{b_{2}^{U}}, \frac{a_{4}^{U}}{b_{1}^{U}} ; \min \left(H_{1}^{U}(a), H_{1}^{U}(b)\right), \min \left(H_{2}^{U}(a), H_{2}^{U}(b)\right)\right) \\
& \left(\frac{a_{1}^{L}}{b_{4}^{L}}, \frac{a_{2}^{L}}{b_{3}^{L}}, \frac{a_{3}^{L}}{b_{2}^{L}}, \frac{a_{4}^{L}}{b_{1}^{L}} ; \min \left(H_{1}^{L}(a), H_{1}^{L}(b)\right), \min \left(H_{2}^{L}(a), H_{2}^{L}(b)\right)\right)
\end{aligned}
$$

\section{Aralık Tip-2 TOPSIS Yöntemi}

TOPSIS yöntemi ilk olarak Hwang ve Yoon(1981) tarafindan önerilen alternatifler arasindaki mesafeleri dikkate alan bir ÇKKV yöntemidir. Yöntem, seçilen en iyi alternatifin pozitif ideal çözüme en kısa mesafeye ve negatif ideal çözüme en uzak mesafeye sahip olması gerektiği mantı̆̆ına dayanmaktadır. Bu alt bölümde, Chen ve Lee (2010a) tarafından önerilen aralık tip-2 bulanık TOPSIS yöntemi, aralık tip-2 bulanık kümeler temelinde ÇKKV problemleri için sunulmuştur.

$X=\left\{x_{1}, x_{2}, \ldots, x_{n}\right\}$ alternatifler kümesi, $F=\left\{f_{1}, f_{2}, \ldots, f_{m}\right\}$ kriterler kümesi ve $k$ uzman $D=$ $\left\{D_{1}, D_{2}, \ldots, D_{k}\right\}$ olduğu varsayılsın. Kriterler kümesi $F_{1}$ and $F_{2}$ olmak üzere iki kümeye ayrilsın. Burada $F_{1}$ fayda kriterleri kümesini, $F_{2}$ maliyet kriterleri kümesini göstermektedir ve $F_{1} \cap F_{2}=\emptyset$ ve $F_{1} \cup F_{2}=F$.

Adım 1: $p$.karar verici için karar matrisi $Y_{p}$ ve ortalama karar matrisi $\bar{Y}$, aşağıdaki gibi oluşturulur: 


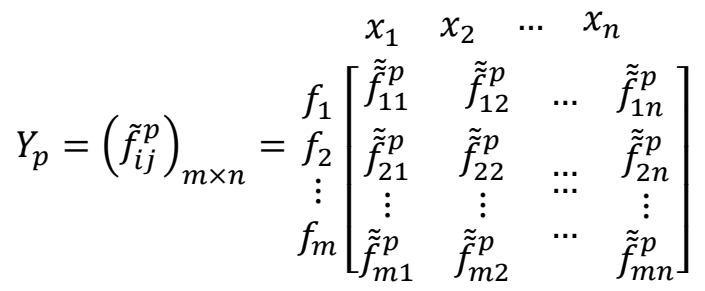

$\bar{Y}=\left(\tilde{f}_{i j}^{p}\right)_{m \times n}$

burada $\tilde{\tilde{f}}_{i j}=\left(\frac{\tilde{\tilde{f}}_{i j}^{1} \oplus \tilde{\tilde{f}}_{i j}^{2} \oplus \cdots \oplus \tilde{\tilde{f}}_{i j}^{k}}{k}\right), \tilde{\tilde{f}}_{i j}$ bir aralık tip-2 bulanık küme iken; $1 \leq i \leq m, 1 \leq j \leq n, 1 \leq p \leq k$, and $k$ karar verici sayısını göstermektedir.

Adım 2:p.karar verici için ağırlık matrisi $W_{p}$ ve ortalama ağırlık matrisi $\bar{W}$, aşağıdaki gibi oluşturulur:

$\left.W_{p}=\left(\widetilde{w}_{i}^{p}\right)_{1 \times m}=\begin{array}{cccc}f_{1} & f_{2} & \cdots & f_{m} \\ \widetilde{w}_{1}^{p} & \widetilde{w}_{2}^{p} & \cdots & \widetilde{w}_{m}^{p}\end{array}\right]$

$\bar{W}=\left(\widetilde{\widetilde{w}}_{i}\right)_{1 \times m}$

burada $\widetilde{\widetilde{w}}_{i}=\left(\frac{\widetilde{w}_{i}^{1} \oplus \widetilde{w}_{i}^{2} \oplus \cdots \oplus \widetilde{w}_{i}^{k}}{k}\right), \widetilde{w}_{i}$ bir aralık tip-2 bulanı küme iken $1 \leq i \leq m, 1 \leq p \leq k, k$ karar verici sayısını gösterir.

Adım 3:A ğırlıklandırılmış karar matrisi $\bar{Y}_{w}$ oluşturulur:

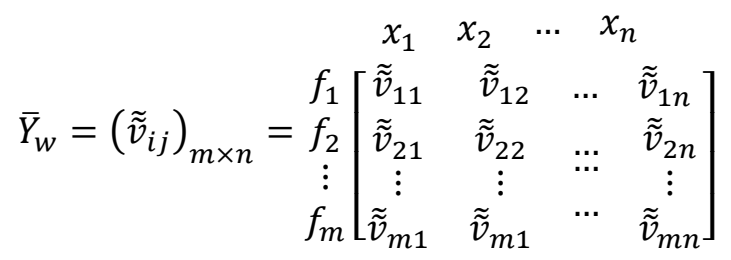

$\operatorname{burada} \tilde{\tilde{v}}_{i j}=\widetilde{\widetilde{w}}_{i} \otimes \tilde{\tilde{f}}_{i j}, 1 \leq i \leq m$ ve $1 \leq j \leq n$.

Adım 4: Aralık tip-2 bulanık küme olan $\tilde{\tilde{v}}_{i j}$ 'nin derecelendirme değeriRank $\left(\tilde{\tilde{v}}_{i j}\right)$ ve sıralı ağırlıklandırlmış karar matrisi $\bar{Y}_{w}^{*}$ hesaplanir.

$\bar{Y}_{w}^{*}=\left(\operatorname{Rank}\left(\tilde{\tilde{v}}_{i j}\right)\right)_{m \times n}$

burada $1 \leq i \leq m, 1 \leq j \leq n$.

Tanım: Aralık tip-2 bulanık küme olan $\tilde{\tilde{A}}_{i}^{\prime}$ nin derecelendirme değeriRank $\left(\tilde{\tilde{A}}_{i}\right)$ aşağıdaki gibi tanımlanmıştır:

$\operatorname{Rank}\left(\tilde{A}_{i}\right)=M_{1}\left(\tilde{A}_{i}^{U}\right)+M_{1}\left(\tilde{A}_{i}^{L}\right)+M_{2}\left(\tilde{A}_{i}^{U}\right)+M_{2}\left(\tilde{A}_{i}^{L}\right)+M_{3}\left(\tilde{A}_{i}^{U}\right)+M_{3}\left(\tilde{A}_{i}^{L}\right)-\frac{1}{4}\left(S_{1}\left(\tilde{A}_{i}^{U}\right)+\right.$ $\left.S_{1}\left(\tilde{A}_{i}^{L}\right)+S_{2}\left(\tilde{A}_{i}^{U}\right)+S_{2}\left(\tilde{A}_{i}^{L}\right)+S_{3}\left(\tilde{A}_{i}^{U}\right)+S_{3}\left(\tilde{A}_{i}^{L}\right)+S_{4}\left(\tilde{A}_{i}^{U}\right)+S_{4}\left(\tilde{A}_{i}^{L}\right)\right)+H_{1}\left(\tilde{A}_{i}^{U}\right)+H_{1}\left(\tilde{A}_{i}^{L}\right)+$ $H_{2}\left(\tilde{A}_{i}^{U}\right)+H_{2}\left(\tilde{A}_{i}^{L}\right)$

burada

$\tilde{\tilde{A}}_{i}=\left(\tilde{A}_{i}^{U}, \tilde{A}_{i}^{L}\right)=\left(\left(a_{i 1}^{U}, a_{i 2}^{U}, a_{i 3}^{U}, a_{i 4}^{U} ; H_{1}\left(\tilde{A}_{i}^{U}\right), H_{2}\left(\tilde{A}_{i}^{U}\right)\right),\left(a_{i 1}^{L}, a_{i 2}^{L}, a_{i 3}^{L}, a_{i 4}^{L} ; H_{1}\left(\tilde{A}_{i}^{L}\right), H_{2}\left(\tilde{A}_{i}^{L}\right)\right)\right)$ bir aralık tip-2 bulanık kümedir. Detaylı bilgi için lütfen bakınız: (Chen \& Lee, 2010a; Erdoğan \& Kaya, 2016).

Adım 5: Pozitif ideal çözüm $x^{+}=\left\{\tilde{v}_{1}^{+}, \tilde{v}_{2}^{+}, \cdots, \tilde{v}_{m}^{+}\right\}$ve negatif ideal çözüm $x^{-}=\left\{\tilde{v}_{1}^{-}, \tilde{v}_{2}^{-}, \cdots, \tilde{v}_{m}^{-}\right\}$, hesaplanir: 


$$
\tilde{v}_{i}^{+}= \begin{cases}\max _{1 \leq j \leq n}\left\{\operatorname{Rank}\left(\tilde{\tilde{v}}_{i j}\right)\right\}, & \operatorname{eg} e r f_{i} \in F_{1} \\ \min _{1 \leq j \leq n}\left\{\operatorname{Rank}\left(\tilde{\tilde{v}}_{i j}\right)\right\}, & \operatorname{eg} \operatorname{erf} f_{i} \in F_{2}\end{cases}
$$

ve

$$
\tilde{v}_{i}^{-}= \begin{cases}\min _{1 \leq j \leq n}\left\{\operatorname{Rank}\left(\tilde{\tilde{v}}_{i j}\right)\right\}, & \text { ĕgerf } f_{i} \in F_{1} \\ \max _{1 \leq j \leq n}\left\{\operatorname{Rank}\left(\tilde{\tilde{v}}_{i j}\right)\right\}, & \text { ĕgerf } f_{i} \in F_{2}\end{cases}
$$

Adım 6: Her bir alternatif $x_{j}$ ve pozitif ideal çözüm $x^{+}$arasındaki mesafe $d^{+}\left(x_{j}\right)$ aşağıdaki gibi hesaplanir.

$d^{+}\left(x_{j}\right)=\sqrt{\sum_{i=1}^{m}\left(\operatorname{Rank}\left(\tilde{\tilde{v}}_{i j}\right)-\tilde{v}_{i}^{+}\right)^{2}}$

burada $1 \leq j \leq n$. Her bir alternatif $x_{j}$ ve negatif ideal çözüm $x^{-}$arasındaki mesafe $d^{-}\left(x_{j}\right)$ aşağıdaki gibi hesaplanir.

$d^{-}\left(x_{j}\right)=\sqrt{\sum_{i=1}^{m}\left(\operatorname{Rank}\left(\tilde{\tilde{v}}_{i j}\right)-\tilde{v}_{i}^{-}\right)^{2}}$

Adım 7: $x_{j}^{\prime}$ ye ait yakınlık katsayısı $C\left(x_{j}\right)$ pozitif ideal çözüm $x^{+}$'ye göre aşağıdaki gibi hesaplanır.

$C\left(x_{j}\right)=\frac{d^{-}\left(x_{j}\right)}{d^{-}\left(x_{j}\right)+d^{+}\left(x_{j}\right)}$

burada $1 \leq j \leq n$.

Adım 8:1 $\leq j \leq n$ iken alternatiflere ait yakınlık katsayıları büyükten küçüğe doğru sıralanır. En büyük $C\left(x_{j}\right)$ katsayısina sahip olan alternatif daha öncelikli olur.

\section{Uygulama: Depo Seçimi}

Bir önceki bölümde sunulan çözüm metodolojisinin uygulaması gerçek bir örnek olay çalışması üzerinde gerçekleştirilmiştir. Bu örnek olay çalışmasında, uluslararası bir firmanın Türkiye'de açılmış olan XYZ (fabrikanın adı gizlilik nedeniyle verilmeyecektir) fabrikasının yöneticileri yeni deponun nerede kurulacağına karar vermede önerilen metodoloji tarafindan desteklenmiştir.

Depo yeri alternatiflerini sıralamak için ele alınan başlıca sorular şunlardır (i) Fabrikanın bölgesindeki aday depolar nelerdir, (i) seçim için karar alma sürecinde göz önünde bulundurulması gereken kriterler nelerdir, (iii) uzmanlara göre belirlenen kriterlerin ağırlıkları nelerdir, (iv) her bir aday deponun her bir kritere göre önemi nedir, (v) farklı aday depoların sıralaması nedir.

\section{Problemin Yapılandırılması}

Alanında uzman akademisyenlerin görüşleri ve yürütülen literatür çalışmalanı sonucunda, yeni deponun karşılanması gereken kriterler ve adaylar belirlenmiştir. Uygulamanın amacı "en iyi depoyu seçmek" olarak belirlenmiştir. Maliyet, konumun özellikleri ve yakınlık ana kriterleri, hiyerarşinin ikinci seviyesine yerleştirilmiş ve toplam 9 alt kriter, karar hiyerarşisinin üçüncü seviyesine yerleştirilmiştir. Dördüncü seviyede alternatif depolar sunulmaktadır. Problem hiyerarşisi Şekil 2'de verilmiştir. 


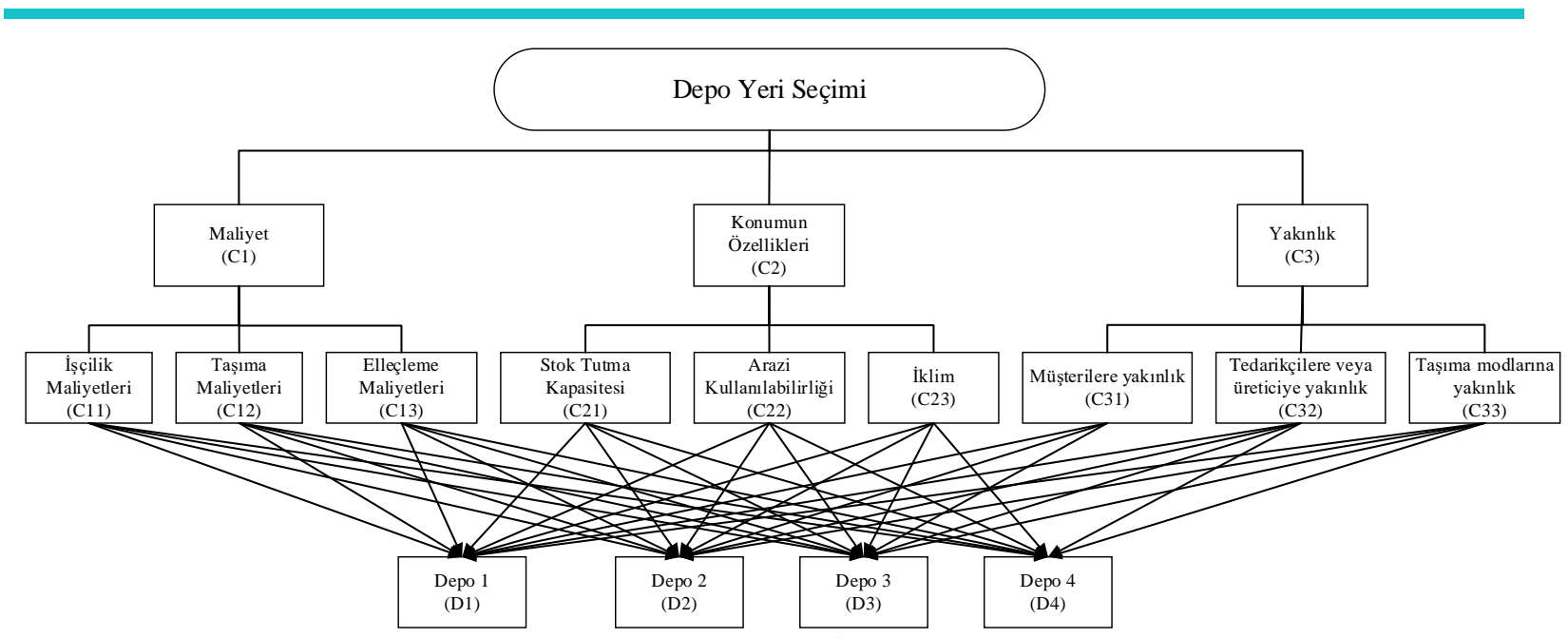

Şekil 3. Hiyerarşik değerlendirme çerçevesi

Karar hiyerarşisi oluşturulduktan sonra, dilsel değişkenler ve ilişkili aralık tip-2 bulanık sayılar tanımlanmıştır. Kriterler ve alt kriterlerin değerlendirmeleri için dilsel değişkenler Tablo 1'de verilmiştir. Alternatiflerin değerlendirmeleri için dilsel değişkenler Tablo 2'de verildiği gibi belirlenmiştir.

Tablo 2. Alternatiflerin Değerlendirilmesi İcin Dilsel Değişkenler (Chené Lee, 2010b, 2010a)

\begin{tabular}{|c|c|}
\hline Dilsel değiskkenler & Aralik tip-2 bulanik sayılar \\
\hline Çok Kötü $(C ̧ K)$ & $((0,0,0,1 ; 1,1),(0,0,0,0.5 ; 0.9,0.9))$ \\
\hline Kötü $(K)$ & $((0,1,1,3 ; 1,1),(0.5,1,1,2 ; 0.9,0.9))$ \\
\hline Biraz Kötü (BK) & $((1,3,3,5 ; 1,1),(2,3,3,4 ; 0.9,0.9))$ \\
\hline $\operatorname{Orta}(\mathrm{O})$ & $((3,5,5,7 ; 1,1),(4,5,5,6 ; 0.9,0.9))$ \\
\hline Biraz İyi (Bİ) & $((5,7,7,9 ; 1,1),(6,7,7,8 ; 0.9,0.9))$ \\
\hline İyi $(\dot{\mathrm{I}})$ & $((7,9,9,10 ; 1,1),(8,9,9,9.5 ; 0.9,0.9))$ \\
\hline Çok İyi (Çİ) & $((9,10,10,10 ; 1,1),(9.5,10,10,10 ; 0.9,0.9))$ \\
\hline
\end{tabular}

\section{Kriter Ağırlıklarının elde edilmesi}

Kriter ağıllıklarını elde etmek için hesaplamaya başlamadan önce, uzmanlara gönderilen anket sonuçlarının tutarlı olup olmadıklarına bakılmıştır. Tutarsızlıklar tespit edilen anketler için uzmanların karşılaştırma matrislerini yeniden değerlendirmeleri istenmiş, ana kriterlerin dilsel değerlendirmeleri Tablo 3 ve alt kriterlerin dilsel değerlendirmeleri Tablo 4'de gösterilmiştir.

Tablo 3. Ana Kriterler İcin Dilsel Değerlendirmeler

\begin{tabular}{llll}
\hline & C1 & C2 & C3 \\
\hline C1 & E, E, E & ÇG, 1/ÇG, BG & OG, 1/OG, 1/OG \\
C2 & & E,E,E & $1 /$ BG, BG, 1/ÇG \\
C3 & & E,E,E \\
\hline
\end{tabular}

Tablo 4. Alt Kriterler İcin Dilsel Değerlendirmeler

$\begin{array}{lllllllll}C 11 & C 12 & C 13 & C 21 & C 22 & C 23 & C 31 & C 32 & C 33\end{array}$

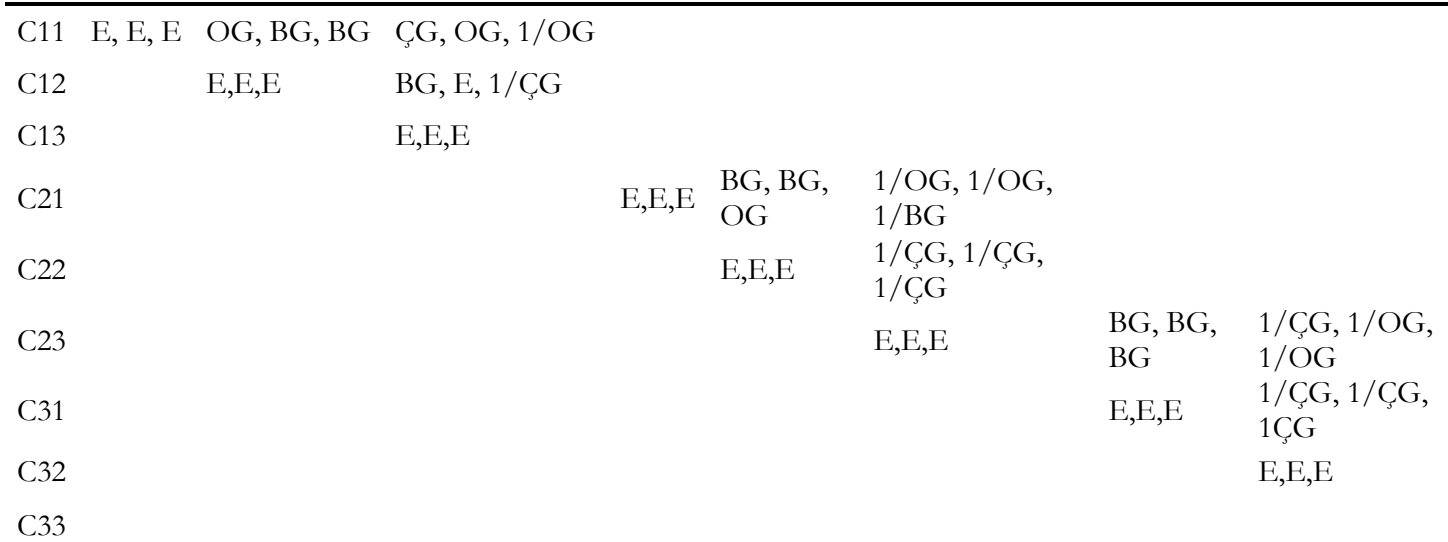


Bulanık ikili karşılaştırma matrislerinin tutarlılığı, ağırlık merkezi (CoA) durulaştırma yöntemi kullanılarak analiz edilmiştir (Kahraman vd. (2014). Durulaştırılmış değerlendirme matrisine göre, ana hem ana kriterler hem de alt kriterler için tutarlılık oranları hesaplanmıştır. Karşılaştırma sonuçları her bir uzman için \%10'dan küçük olduğu için yeniden değerlendirmelere ihtiyaç duyulmamıştır.

Üç farklı uzmanın değerlendirmeleri toplanarak, ikili karşılaştırmalar için üç bulanık sayının geometrik ortalaması, Essitlik (10) ve (11) tarafindan elde edilmiştir. Eşitlik (12) ve (13) kullanılarak kriterlerinin bulanık ağırlıklanı Tablo 5'de verildiği gibi elde edilmiştir.

Tablo 5. Ana ve Alt Kriterlerin Aralık Tip-2 Bulanı Ağırlılar

\begin{tabular}{ll}
\hline & Aralik tip-2 bulan1k ağıtliklat \\
\hline C1 & $(0.156,0.224,0.402,0.557 ; 1,1),(0.170,0.238,0.379,0.518 ; 0.8,0.8)$ \\
C2 & $(0.117,0.167,0.315,0.479 ; 1,1),(0.127,0.177,0.293,0.434 ; 0.8,0.8)$ \\
C3 & $(0.234,0.344,0.646,0.934 ; 1,1),(0.256,0.367,0.606,0.859 ; 0.8,0.8)$ \\
C11 & $(0.270,0.408,0.755,1.044 ; 1,1),(0.298,0.437,0.712,0.973 ; 0.8,0.8)$ \\
C12 & $(0.097,0.133,0.242,0.371 ; 1,1),(0.104,0.140,0.226,0.335 ; 0.8,0.8)$ \\
C13 & $(0.157,0.204,0.345,0.492 ; 1,1),(0.166,0.214,0.325,0.453 ; 0.8,0.8)$ \\
C21 & $(0.107,0.156,0.301,0.453 ; 1,1),(0.117,0.173,0.279,0.413 ; 0.8,0.8)$ \\
C22 & $(0.047,0.060,0.108,0.169 ; 1,1),(0.050,0.065,0.097,0.151 ; 0.8,0.8)$ \\
C23 & $(0.380,0.533,0.925,1.250 ; 1,1),(0.411,0.573,0.857,1.170 ; 0.8,0.8)$ \\
C31 & $(0.088,0.130,0.233,0.320 ; 1,1),(0.097,0.138,0.220,0.299 ; 0.8,0.8)$ \\
C32 & $(0.049,0.060,0.103,0.161 ; 1,1),(0.051,0.063,0.096,0.145 ; 0.8,0.8)$ \\
C33 & $(0.469,0.601,0.928,1.169 ; 1,1),(0.495,0.630,0.886,1.113 ; 0.8,0.8)$ \\
\hline
\end{tabular}

\section{Alternatiflerin Siralanması}

Kriterlerin bulanık ağırlıkları belirlendikten sonra alternatifler aralık tip-2 bulanık TOPSIS yaklaşımı ile değerlendirilmiştir. Öncelikle uzmanlar, önceki aşamada belirtilen her bir alt-kriterle ilgili her bir alternatifin bulanık değerlendirmelerini vermişlerdir. Tablo 6'da uzmanlar tarafindan sağlanan karar matrisi, gösterilmiştir. Dilsel değişkenlerin bulanık eşitlikleri kullanılarak, Denklem (14) ve (15)'de verilen ortalama karar matrisi belirlenmiştir.

Tablo 6. Beş Alternatif İçin Dilsel Değerlendirmeler

\begin{tabular}{|c|c|c|c|c|}
\hline & Denolar & $U_{z n}$ & & \\
\hline & Depolat & $U 1$ & $U 2$ & U3 \\
\hline & D1 & $\mathrm{O}$ & BK & $\mathrm{BK}$ \\
\hline & D2 & $\mathrm{O}$ & $\mathrm{O}$ & $\mathrm{O}$ \\
\hline C11 & D3 & $\mathrm{K}$ & $\dot{I}$ & Bİ \\
\hline & D4 & $\mathrm{K}$ & ÇK & $\mathrm{K}$ \\
\hline & D1 & $\mathrm{K}$ & $\dot{\mathrm{I}}$ & $\mathrm{BK}$ \\
\hline & D2 & $\mathrm{O}$ & $\dot{\mathrm{I}}$ & Bİ \\
\hline C12 & D3 & Çİ & $\mathrm{O}$ & Ç்ं \\
\hline & D4 & $\mathrm{BK}$ & Bİ & $\mathrm{O}$ \\
\hline & D1 & $\mathrm{BK}$ & $\mathrm{O}$ & $\dot{\mathrm{I}}$ \\
\hline & D2 & Çİ & $\mathrm{O}$ & $\dot{\mathrm{I}}$ \\
\hline C13 & D3 & $\mathrm{O}$ & $\dot{\mathrm{I}}$ & $\dot{\mathrm{I}}$ \\
\hline & D4 & $\mathrm{O}$ & $\mathrm{K}$ & $\dot{\mathrm{I}}$ \\
\hline & D1 & $\dot{\mathrm{I}}$ & Bİ & Bİ \\
\hline & D2 & $\mathrm{O}$ & BK & $\mathrm{BK}$ \\
\hline C21 & D3 & Bİ & $\mathrm{O}$ & $\mathrm{O}$ \\
\hline & D4 & $\dot{\mathrm{I}}$ & Bİ & Bİ \\
\hline
\end{tabular}




\begin{tabular}{|c|c|c|c|c|}
\hline \multirow{4}{*}{ C22 } & D1 & $\dot{\mathrm{I}}$ & $\mathrm{BI}$ & BI \\
\hline & D2 & $\mathrm{K}$ & Bİ & $\dot{\mathrm{I}}$ \\
\hline & D3 & $\mathrm{O}$ & K & BK \\
\hline & D4 & Bİ & $\mathrm{K}$ & $\dot{\mathrm{I}}$ \\
\hline \multirow{4}{*}{ C23 } & D1 & Ç̇ं & Ç் & $\dot{\mathrm{I}}$ \\
\hline & D2 & Bİ & $\dot{\mathrm{I}}$ & BK \\
\hline & D3 & Bİ & $\mathrm{O}$ & $\mathrm{K}$ \\
\hline & D4 & İ & BK & $\mathrm{K}$ \\
\hline \multirow{4}{*}{ C31 } & D1 & Çİ & $\mathrm{O}$ & Çİ \\
\hline & D2 & $\mathrm{BI}$ & Bİ & Bİ \\
\hline & D3 & $\mathrm{O}$ & Çİ & $\dot{\mathrm{I}}$ \\
\hline & D4 & $\mathrm{K}$ & $\mathrm{BK}$ & $\mathrm{O}$ \\
\hline \multirow{4}{*}{ C32 } & D1 & $\dot{\mathrm{I}}$ & BK & $\dot{\mathrm{I}}$ \\
\hline & D2 & $\mathrm{BK}$ & $\mathrm{O}$ & Bİ \\
\hline & D3 & $\mathrm{K}$ & $\mathrm{O}$ & $\dot{\mathrm{I}}$ \\
\hline & D4 & $\mathrm{BK}$ & $\dot{\mathrm{I}}$ & $\mathrm{BK}$ \\
\hline \multirow{4}{*}{ C33 } & D1 & Bİ & $\mathrm{O}$ & $\dot{\mathrm{I}}$ \\
\hline & D2 & $\mathrm{K}$ & $\mathrm{K}$ & $\mathrm{K}$ \\
\hline & D3 & $\dot{\mathrm{I}}$ & $\dot{\mathrm{I}}$ & Bİ \\
\hline & D4 & Bİ & $\mathrm{K}$ & Bİ \\
\hline
\end{tabular}

Denk. 18 ile ağırlıklandırılmıss karar matrisi hesaplanmış ve Tablo 7'de sunulmuştur.

Tablo 7. Ağrrliklandirlmıs Karar Matrisi

\begin{tabular}{|c|c|c|}
\hline Alt-kriterler & Depolar & \\
\hline \multirow{4}{*}{ C11 } & D1 & $(0.007,0.033,0.111,0.330 ; 1,1),(0.013,0.038,0.099,0.235 ; 0.8,0.8)$ \\
\hline & D2 & $(0.013,0.046,0.152,0.407 ; 1,1),(0.020,0.052,0.135,0.303 ; 0.8,0.8)$ \\
\hline & D3 & $(0.017,0.052,0.172,0.427 ; 1,1),(0.024,0.059,0.153,0.328 ; 0.8,0.8)$ \\
\hline & D4 & $(0.000,0.006,0.020,0.136 ; 1,1),(0.002,0.007,0.018,0.076 ; 0.8,0.8)$ \\
\hline \multirow{4}{*}{ C12 } & D1 & $(0.004,0.013,0.042,0.124 ; 1,1),(0.006,0.014,0.037,0.090 ; 0.8,0.8)$ \\
\hline & D2 & $(0.008,0.021,0.068,0.179 ; 1,1),(0.011,0.023,0.060,0.136 ; 0.8,0.8)$ \\
\hline & D3 & $(0.011,0.025,0.081,0.186 ; 1,1),(0.014,0.028,0.071,0.151 ; 0.8,0.8)$ \\
\hline & D4 & $(0.005,0.015,0.049,0.145 ; 1,1),(0.007,0.017,0.043,0.104 ; 0.8,0.8)$ \\
\hline \multirow{4}{*}{ C13 } & D1 & $(0.009,0.026,0.079,0.201 ; 1,1),(0.013,0.029,0.070,0.153 ; 0.8,0.8)$ \\
\hline & D2 & $(0.016,0.037,0.111,0.247 ; 1,1),(0.020,0.041,0.099,0.200 ; 0.8,0.8)$ \\
\hline & D3 & $(0.014,0.035,0.106,0.247 ; 1,1),(0.019,0.039,0.094,0.196 ; 0.8,0.8)$ \\
\hline & D4 & $(0.008,0.023,0.069,0.183 ; 1,1),(0.012,0.026,0.062,0.137 ; 0.8,0.8)$ \\
\hline \multirow{4}{*}{$\mathrm{C} 21$} & D1 & $(0.007,0.020,0.073,0.203 ; 1,1),(0.010,0.024,0.063,0.152 ; 0.8,0.8)$ \\
\hline & D2 & $(0.002,0.010,0.035,0.123 ; 1,1),(0.004,0.011,0.030,0.084 ; 0.8,0.8)$ \\
\hline & D3 & $(0.005,0.015,0.054,0.181 ; 1,1),(0.007,0.017,0.046,0.119 ; 0.8,0.8)$ \\
\hline & D4 & $(0.007,0.020,0.073,0.203 ; 1,1),(0.010,0.024,0.063,0.152 ; 0.8,0.8)$ \\
\hline \multirow{4}{*}{$\mathrm{C} 22$} & D1 & $(0.003,0.008,0.026,0.075 ; 1,1),(0.004,0.009,0.022,0.056 ; 0.8,0.8)$ \\
\hline & D2 & $(0.002,0.006,0.019,0.059 ; 1,1),(0.003,0.007,0.016,0.043 ; 0.8,0.8)$ \\
\hline & D3 & $(0.001,0.003,0.005,0.040 ; 1,1),(0.001,0.003,0.009,0.026 ; 0.8,0.8)$ \\
\hline & D4 & $(0.002,0.006,0.019,0.059 ; 1,1),(0.003,0.007,0.016,0.043 ; 0.8,0.8)$ \\
\hline \multirow{4}{*}{$\mathrm{C} 23$} & D1 & $(0.037,0.086,0.281,0.599 ; 1,1),(0.047,0.098,0.243,0.499 ; 0.8,0.8)$ \\
\hline & $\mathrm{D} 2$ & $(0.013,0.044,0.146,0.419 ; 1,1),(0.021,0.051,0.126,0.305 ; 0.8,0.8)$ \\
\hline & D3 & $(0.012,0.038,0.126,0.379 ; 1,1),(0.018,0.044,0.109,0.271 ; 0.8,0.8)$ \\
\hline & D4 & $(0.012,0.038,0.126,0.359 ; 1,1),(0.018,0.044,0.109,0.262 ; 0.8,0.8)$ \\
\hline \multirow{4}{*}{ C31 } & D1 & $(0.014,0.037,0.126,0.269 ; 1,1),(0.019,0.042,0.111,0.223 ; 0.8,0.8)$ \\
\hline & D2 & $(0.010,0.031,0.105,0.269 ; 1,1),(0.015,0.036,0.093,0.206 ; 0.8,0.8)$ \\
\hline & D3 & $(0.013,0.036,0.121,0.269 ; 1,1),(0.018,0.041,0.107,0.218 ; 0.8,0.8)$ \\
\hline & D4 & $(0.003,0.013,0.020,0.150 ; 1,1),(0.005,0.015,0.040,0.103 ; 0.8,0.8)$ \\
\hline
\end{tabular}




\begin{tabular}{lll} 
& D1 & $(0.006,0.014,0.047,0.125 ; 1,1),(0.008,0.016,0.041,0.095 ; 0.8,0.8)$ \\
C32 & $(0.003,0.010,0.033,0.105 ; 1,1),(0.005,0.012,0.029,0.074 ; 0.8,0.8)$ \\
& D2 & $(0.004,0.010,0.033,0.100 ; 1,1),(0.005,0.012,0.029,0.072 ; 0.8,0.8)$ \\
& D3 & $(0.003,0.010,0.033,0.100 ; 1,1),(0.005,0.012,0.029,0.072 ; 0.8,0.8)$ \\
\hline & D4 & $(0.055,0.145,0.419,0.947 ; 1,1),(0.076,0.162,0.376,0.749 ; 0.8,0.8)$ \\
C33 & $(0.000,0.014,0.040,0.328 ; 1,1),(0.006,0.023,0.054,0.191 ; 0.8,0.8)$ \\
& D2 & $(0.070,0.172,0.499,1.056 ; 1,1),(0.093,0.193,0.447,0.861 ; 0.8,0.8)$ \\
& D3 & $(0.037,0.103,0.300,0.765 ; 1,1),(0.053,0.116,0.268,0.574 ; 0.8,0.8)$ \\
\hline
\end{tabular}

Depoların derecelendirme değerleri Denk. (19) ve (20) kullanılarak elde edilmiştir. Daha sonra Denk. (21) ve (22) kullanılarak sırasıyla pozitif ve negatif ideal çözüm hesaplanmıştır. Pozitif ve negatif ideal çözümlerden uzaklıklar Denklemler kullanılarak (23) ve (24) kullanılarak elde edilmiş ve Tablo 8'de sunulmuştur. Son olarak, Denk. (25) ile yakınlık indeksi ve sıralama sonuçları Tablo 8'de görüldügü gibi elde edilmişsir. Sonuçlara göre, D1 deposu değerlendirme kriterleri açısından en uygun depodur.

Tablo 8. Dört Alternatifin Yakinlik Katsaynlar

\begin{tabular}{lcccc}
\hline Depolar & $\boldsymbol{d}^{+}\left(\boldsymbol{x}_{\boldsymbol{j}}\right)$ & $\boldsymbol{d}^{-}\left(\boldsymbol{x}_{\boldsymbol{j}}\right)$ & $\boldsymbol{C}\left(\boldsymbol{x}_{\boldsymbol{j}}\right)$ & \multicolumn{2}{c}{ Siralama } \\
\hline D1 & 0.444 & 0.745 & 0.627 & 1 \\
D2 & 0.506 & 0.734 & 0.592 & 3 \\
D3 & 0.558 & 0.812 & 0.593 & 2 \\
D4 & 0.988 & 0.164 & 0.143 & 4 \\
\hline
\end{tabular}

\section{Sonuç}

Depo yeri seçimi, tedarik zinciri yönetiminde yönetimsel karar vermenin stratejik bir parçasıdır. Çoğu durumda, tedarik zincirinin başarısı ve hayatta kalması, depo yerinin önceden planlanmış seçimine bağlıdır. $\mathrm{Bu}$ nedenle, piyasadaki katı rekabette ayakta kalmak için, depo yeri seçim prosedürlerinin sürekli ve uygun bir şekilde değerlendirilmesi gereklidir. Bu yazıda ilgimiz aralıklı tip-2 bulanık ortam altında depo yeri seçimi değerlendirmesidir. Yeni depoların tercih sırasını tahmin etmek ve böylece satın alma için en karlı olanı tanımlamak çalışmanın hedefini oluşturmaktadır.

Gerçek hayattaki karar verme süreçlerinde karar vericiler, tercihlerini tam olarak net değerlerle ifade edememekte ve değerlendirmelerini sıklıkla dilsel olarak ifade etmektedirler. Bu gibi durumlarda, bulanık küme teorisi, bu tür bir problemle başa çıkmak için uygun bir araçtır. Problemin doğasında olan belirsizliği en iyi şekilde yansıtmak için aralık tip-2 bulanık kümeler uygulanmaktadır. Bu çalışmada, bulanık ÇKKV'ne dayanarak, en uygun depo yeri seçimi analiz edilmiştir. Bu amaçla, tip-2 bulanık kümeleri temel alan ve AHP ve TOPSIS yöntemlerinden oluşan bütünleşik bir ÇKKV metodolojisi önerilmiştir. İlk olarak, literatür taraması ve uzman görüşleri ile depo yeri seçimine etki eden kriterler sonuçlandırılmış, üç ana kriter ve dokuz alt kriterin belirlenmesinden sonra, kriterlerin ağırlıkları aralık tip-2 bulanık AHP yöntemi ile belirlenmiştir. Buna göre, depo yeri seçimi için "yakınlı" en önemli ana kriter, "taşıma modlarına yakınlık" ise en önemli alt kriter olarak ortaya çıkmış ve bu sonuçlar geçmişteki birkaç çalışma ile uyumlu elde edilmiştir (Kabak ve Keskin, (2018); Dey vd. (2016)). Ancak, Özcan vd. (2011) en önemli kriter olarak stok tutma kapasitesi, Karmaker ve Saha, (2015) ulaştırma durumu, ve Demirel vd.(2010) maliyetler ve altyap1 olarak elde etmiştir. Benzer şekilde "konumun özelikleri" kriteri uzmanlarca en az ağırlığa sahip bulunmuş ve bu sonuç depo seçiminde yakınlık ve maliyet kriterlerine oranla çok fazla dikkate alınmadığı gözlemlenmiştir. Son aşamada, aralık tip-2 bulanık TOPSIS yöntemini kullanarak bu kriterlere göre dört alternatif deponun sıralaması yapılmış ve sonuçlar uygulamadaki firma için en iyi alternatif olarak D1 deposu olduğunu göstermiştir. Sonuçlar, aralık tip-2 bulanık ÇKKV metodolojisi, depo yeri seçimi analizi için potansiyel yerlerin seçiminde karar vericiler için yararlı bir araç olduğunu göstermektedir.

Gelecekteki çalışmalarda önerilen metodoloji, depo seçimini değerlendirmek ve sıralamak için kullanılabilir ve diğer mevcut metodolojiler ile karşılaştırılabilir. Ayrıca diğer bulanık kümeler ve farklı ÇKKV teknikleri önerilen yönteme dâhil edilebilir ve depo yer seçimi bağlamında gelecekteki araştırmalara olanak sağlayabilir. Hibrit yöntemin doğast ile ilgili olarak, tedarikçi seçimi, personel seçimi ve üçüncü parti lojistik sağlayıcı gibi çeşitli yönetim sorunlarını çözmek için diğer karar verme problemlerinde kullanılabilir. 


\section{Kaynakça}

Aktepe, A. ve Ersöz, S. (2014). AHP-VIKOR ve MOORA Yöntemlerinin depo yeri seçim probleminde uygulanması. Endüstri Mühendisliği Dergisi, 25(1-2), 2-15.

Ashrafzadeh, M., Mokhatab rafiei, F., Mollaverdi, N. ve Zare, Z. (2012). Application of fuzzy TOPSIS method for the selection of W arehouse Location: A Case Study. Interdiscipl J Contemp Res Business (C. 3).

Asır, Ö. ve Erol, E. (2016). COPRAS ve MOORA Yöntemlerinin depo yeri seçim problemine uygulanmasi. Ekonomi, Isletme, Siyaset ve Uluslararasi Iliskiler Dergisi (JEBPIR), 2(1), 23-42.

Baykasoğlu, A. ve Gölcük, İ. (2017). Development of an interval type-2 fuzzy sets based hierarchical MADM model by combining DEMATEL and TOPSIS. Expert Systems with Applications, 70, 37 51.https://doi.org/10.1016/J.ESWA.2016.11.001

Buckley, J. J. (1985). Fuzzy hierarchical analysis. Fuzzy Sets and Systems, 17(3), $233-247$. https://doi.org/10.1016/0165-0114(85)90090-9

Büyüközkan, G. ve Uztürk, D. (2017). Combined QFD TOPSIS approach with 2-tuple linguistic information for warehouse selection. Içinde 2017 IEEE International Conference on Fuzzy Systems (FUZZ-IEEE) (ss. 1-6). https://doi.org/10.1109/FUZZ-IEEE.2017.8015684

Chai, J., Liu, J. N. K. ve Xu, Z. (2013). A rule-based group decision model for warehouse evaluation under intervalvalued Intuitionistic fuzzy environments. Expert Systems with Applications, 40(6), 1959-1970. https://doi.org/10.1016/J.ESWA.2012.10.003

Chen, C. T. (2001). A fuzzy approach to select the location of the distribution center. Furzy Sets and Systems, 118(1), 65-73. https://doi.org/10.1016/S0165-0114(98)00459-X

Chen, S. M. ve Lee, L. W. (2010a). Fuzzy multiple attributes group decision-making based on the interval type-2 TOPSIS method. Expert Systems with Applications, 37(4), 2790-2798. https://doi.org/10.1016/j.eswa.2009.09.012

Chen, S. M. ve Lee, L. W. (2010b). Fuzzy multiple attributes group decision-making based on the ranking values and the arithmetic operations of interval type-2 fuzzy sets. Expert Systems with Applications, 37(1), 824-833. https://doi.org/10.1016/j.eswa.2009.06.094

Çelik, E., Bilisik, O. N., Erdogan, M., Gumus, A. T. ve Baracli, H. (2013). An integrated novel interval type-2 fuzzy MCDM method to improve customer satisfaction in public transportation for Istanbul. Transportation Research Part E: Logistics and Transportation Review, 58, 28-51. https://doi.org/10.1016/J.TRE.2013.06.006

Demirel, T., Demirel, N. C.. ve Kahraman, C. (2010). Multi-criteria warehouse location selection using Choquet integral. Expert Systems with Applications, 37(5), 3943-3952. https://doi.org/10.1016/J.ESWA.2009.11.022

Dey, B., Bairagi, B., Sarkar, B. ve Sanyal, S. K. (2013). A hybrid fuzzy technique for the selection of warehouse location in a supply chain under a utopian environment. International Journal of Management Science and Engineering Management, 8(4), 250-261. https://doi.org/10.1080/17509653.2013.825075

Dey, B., Bairagi, B., Sarkar, B. ve Sanyal, S. K. (2016). Warehouse location selection by fuzzy multi-criteria decision making methodologies based on subjective and objective criteria. International Journal of Management Science and Engineering Management, 11(4), 262-278. https://doi.org/10.1080/17509653.2015.1086964

Erdoğan, M. ve Kaya, İ. (2016). A combined fuzzy approach to determine the best region for a nuclear power plant in Turkey. Applied Soft Computing, 39, 84-93. https://doi.org/10.1016/J.ASOC.2015.11.013

Frazelle, E. (2015). Supply chain strategy. McGraw Hill.

Huang, S., Wang, Q., Batta, R. ve Nagi, R. (2015). An integrated model for site selection and space determination of warehouses. Computers \& Operations Research, 62, 169-176. https://doi.org/10.1016/J.COR.2014.10.015

Hwang, C. L. ve Yoon, K. (1981). Multiple attribute decision making: methods and applications. Springer-Verlag. Tarihinde adresinden erişildi https://books.google.com.tr/books?id=X-wYAQAAIAAJ

Jha, M., Raut, R., B. Gardas, B. ve Raut, V. (2018). A sustainable warehouse selection: An interpretive structural modelling approach. International Journal of Procurement Management (C. 11). https://doi.org/10.1504/IJPM.2018.090025

Kabak, M. ve Keskin, İ. (2018). Hazardous Materials Warehouse Selection Based on GIS and MCDM. Arabian Journal for Science and Engineering, 43(6), 3269-3278. https://doi.org/10.1007/s13369-018-3063-z

Kahraman, C., Öztayşi, B., Uçal Sarı, İ. ve Turanoğlu, E. (2014). Fuzzy analytic hierarchy process with interval type-2 fuzzy sets. Knowledge-Based Systems, 59, 48-57. https://doi.org/10.1016/J.KNOSYS.2014.02.001

Karmaker, C. ve Saha, M. (2015). Optimization of warehouse location through fuzzy multi-criteria decision making methods. Decision Science Letters (C. 4). https://doi.org/10.5267/j.dsl.2015.4.005

Özcan, T., Çelebi, N. ve Esnaf, Ş. (2011). Comparative analysis of multi-criteria decision making methodologies and implementation of a warehouse location selection problem. Expert Systems with Applications, 38(8), 9773-9779. https://doi.org/10.1016/J.ESWA.2011.02.022

Vlachopoulou, M., Silleos, G. ve Manthou, V. (2001). Geographic information systems in warehouse site selection decisions. International Journal of Production Economics, 71(1-3), 205-212. https://doi.org/10.1016/S09255273(00)00119-5 
Logistics and supply chain management perform a key role in today's global market. The supply chain includes various nodes between networks and transportation of products is very critical between nodes. Nodes consist of suppliers, facilities, warehouses, distribution centers, and customers (Dey, et al., 2016). The most important stage of demonstrating an effective distribution network is the selection of warehouse locations. The location of a warehouse is mostly one of the most important and strategic decisions in supply chain optimization. It is a long-term decision and is influenced by many quantitative and qualitative criteria. However, some of the criteria are so important that they become dominant in the decisions.

The problem of warehouse location selection is a typical Multi Criteria Decision Making (MCDM) problem that includes conflicting criteria such as political environment, proximity to markets and customers, supplier networks, expansion potential, availability of transportation systems, quality of service, quality of life, and cultural problems. Since evaluations of decision makers are expressed by linguistic judgments and subjective, the crisp values will not be accurate solution. Therefore, MCDM methods are combined with fuzzy set theory in this study (Baykasoğlu, \& Gölcük, 2017). However, since type-2 fuzzy sets can cope with more uncertainty and produce more reliable results (Celik, et al., 2013), they are often used to model uncertain information of decision makers.

This study aims to specify best warehouse location using a MCDM methodology based on interval type-2 fuzzy sets. The methodology is employed to compare four alternative warehouses for a company operating in the aluminum sector in Turkey. For this purpose, AHP and TOPSIS methods are applied under the interval type- 2 fuzzy environment to find the best alternative location. In the evaluation process, criteria weights are calculated using the interval type-2 fuzzy AHP method and ranking of the alternatives are acquired by using the interval type-2 fuzzy TOPSIS method.

The proposed methodology consists of three basic steps: (1) Defining criteria, alternatives and linguistic variables to be used in the model; (2) Using the interval type-2 AHP method to determine criteria weights; (3) Applying the interval type-2 fuzzy TOPSIS method to rank the alternatives.

The application of the proposed methodology was carried out on a real case study. In this case study, managers of an international company which opened a new factory in Turkey were supported by proposed methodology for deciding where to set up the new warehouse.

As a result of opinions of the academicians who are experts in their field and the conducted literature review, criteria and alternatives are determined. The purpose of the application is to select the best warehouse location. Cost, location features, and proximity were placed at the second level of the hierarchy as main criteria and nine sub-criteria are settled in the third level of the decision hierarchy. Alternative warehouses are provided at the fourth level.

After the decision hierarchy was established, the linguistic variables and the associated interval type-2 fuzzy numbers were defined. The evaluations of three different experts were collected and the geometric mean of the three fuzzy numbers for pairwise comparisons was calculated and the fuzzy weights of the criteria were obtained as given in Table 5. According to expert opinions, the weights of the criteria were observed as "proximity" (0.47), "cost" $(0.30)$ and "location features" $(0.23)$ respectively.

Thereafter determining the fuzzy weights of the criteria, the alternatives were evaluated by the interval type-2 fuzzy TOPSIS method. First, experts indicated fuzzy evaluations of the relevant alternatives according to each sub-criterion, and then the interval type-2 fuzzy TOPSIS method is employed to rank the alternatives. According to the results, warehouse D1 is acquired the most appropriate warehouse in terms of evaluations.

In this study, the most appropriate warehouse location selection is analyzed based on the fuzzy MCDM methods. For this purpose, an integrated MCDM methodology consists of AHP and TOPSIS methods based on interval type-2 fuzzy sets is proposed. First of all, regarding literature review and expert opinions, the criteria affecting the selection of warehouse location are finalized. After three main criteria and nine sub-criteria are determined, the weights of the criteria are calculated by the interval type- 2 fuzzy AHP method. Accordingly, the most important main criterion is found as "proximity" and "proximity to transportation modes" has emerged as the most important sub-criterion and these are obtained in accordance with several previous studies (Kabak, \& Keskin, (2018); Dey et al. (2016). However, Özcan, et al., (2011) detected holding capacity, Karmaker, \& Saha, (2015) discovered transport status; and Demirel, et al., (2010) obtained costs and infrastructure that are the most important criteria for warehouse location 
selection. In the last stage, using the interval type-2 fuzzy TOPSIS method, four alternative warehouses are ranked according to these criteria and the results showed that D1 is the best alternative for the application company. The results show that the interval-2 fuzzy MCDM methodology is a useful tool for decision makers in the selection of potential locations for warehouse locations election analysis. 